\title{
Aggresion of Teenagers in Albania
}

\author{
Ida Kruti \\ European University of Tirana \\ Faculty of Social Sciences and Communication, PhD Programs \\ Tel.00355(0)69 2522984 \\ ida_t2002@yahoo.de
}

\begin{abstract}
In general terms, this study examined the "Aggression of teenagers in Albania". These are the first result of one empirical national research. The reason that I chose this subject expresses my interests toward the deeper recognition of the teenager as well as some of the main phenomena that accompany individual development. We will analyzing teenagers as humans in the context of Bio-Psycho-Social capacity, which can be performed only by the science of psychology. The idividual development associated with biological changes, vital functions, the teenagers' relationship between society and family remain an important area of study for many sciences. Numerous adolescents stay in this phase, the more difficulties have to be overcome due to with rapid adjustments of the body changes, the longer will continue the family conflicts or their efforts to position themselves in the society. Adolescence itself is a painful process, where teenagers leaves behind the childhoodperiod and move towards a new path where the individual creates the new identity in the family and society. In this paper we will deal with teenagers' behaviour as the principal focus of research: The main issues to be addressed in this work are as follows: 1. The concept of aggression an attempt to study it, according to biological, cognitive-behavioural, psychoanalytic theories, etc. 2. Antisocial behaviour and its characteristics. The most risky age groups. 3. The causes of aggression and antisocial behaviour during the adolescence period. 4. Explanation of the concept of adolescence, when it starts in terms of gender comparison, its characteristics, problems and difficulties that occur to selected specific ages. Description and types of interpersonal relations established with the family and social groups. 5. Information about the spread of both phenomena by specifying which of the stages of adolescence is more risked in terms of gender division (girls or boys). Significant statistic about aggression of adolescents girls in our society is problematic. Recognizing the difficulties of inclusion in some specific aspects of this age period and associated phenomena such as aggression the goal of my work is to analyze these phenomena and their social impact. One of the goals my research is to present and describe trends that are noticed currently in the lives of young people in the Albanian society. Special attention is paid to the theoretical analysis and the statistical data in order to identify the tendency of adolescents, with regard to the expression of aggression in the Albanian society. The ful study includes 816 girls and boys and I want to present the first results, that involved 250 students, 17 year old. Participants 108 males and 142 females. This study reported a high level of aggression among female and male adolescents. The used test is the BussDurkee Hostility Inventory (BDHI, 1957). Castrogiovanni P, Andreani M.F. et al. (1982); Castrogiovanni P., Maremmanil (1993)" reworked again "Buss and Perry and updated by Buss and Warren (2000)". This test is the most widely used selfreport assessment of aggression, was used in different populations and cultures, with a purpose to show the level of aggression and to understand how gender influences to different kinds of aggression( Yudofsky, S \& Hales, R., 2008).
\end{abstract}

Keywords: Aggression, Albania, Adolescence, Boys and Girls.

\section{Introduction}

Task of psychology is to analyze conflicts that arise during adolescence this age stage. It is generally agreed that these important developments affecting the bio-psycho-social status, and consequently reflected in their psyches. Adolescent sexual developed and established is in a state of transition to create his personality, cognitive and intellectual changes. This dramatic change and teens social status are in crisis he lives between being a child and adult. Biological differences lie in the focus of psychology because they are often the cause of phenomena that are social interest (Wohlman, B. B.1998). To the attention of psychology remain perceptions, emotions, motivations, social behaviour, and mental development trials that come as a result of physiological development during adolescence. To understand the psychology of adolescence is like to see it as a process variable of learning, intellectual organization, personal judgment, age trend, its status as sexual as well as social and economic(Ausubel P. David, 2002). 
The focus of the study of adolescence in psychological plan, the remains in fact to understanding adolescents and their problems( Myers, G.D., 1999 "Socialpsikologjia"). All the phenomena observed from the age of $13-19$ years, ranging from sexual relations with or without prejudice, drug abuse or dependence and its social consequences in the context of crime. As one of the key tasks to the attention of psychologists remains sensitize the population. By this mean not only those who are in direct relationship with the teenagers whether they are teachers, parents and counselors, but all of society should be able to understand and explain these behaviours. Whenever it comes to adolescence or want to remember this period of life everyone of us conjure up a vital period in charge not only emotions but also in conflict. Someone says "earthquake" someone "not me", "was not the time that it is today", "beautiful", "full of emotion" did not understand why I cried and argued so much "," with no one seemed to understand" Although adolescence is perceived with such comments from all adults they soon are not afraid to say that their behavior have been less aggressive compared with that of today's generation. How true is this? It is difficult to say because there is no data for the period of communism, as youth education consisted in the preparation of revolutionary individual. If will refer to the human being that owns aggressiveness at birth. Early childhood aggression displayed in verbal form, this condition manifests itself more or less the same levels as boys and girls, these are forms of open aggression, and later is generally hidden. ( Delfos 2004;Gemeli,1996). In the first two years of life, when aggresion first amerges in the human repertoire, sex differences are not pronounced(Hay, 2005). In the school age males are more aggressive than females (Kim - Cohen, 2005). Different studies have shown that girls would display and receive more relational aggression(kinf of nonverbal aggresion) compared to boys, espencially during interactions with females (Ostrov \& Keating, 2004).

In a study in USA (2002) for physical, verbal and indirect aggression of adolescents, resulted that one in five children bullied others, and more than one in three high school students were involved in some form of physical attack. About $30-40 \%$ of males adolescents and $16-32 \%$ of females were involved in criminal, violent acts by the age of 17 . (National Youth Violence Prevention Ressource Center, 2002). According to another empiric study in USA which included 73.498 adolescents which refered to the difference between genders. This study showed that the difference between the physical agression of boys was higher than the girls and the verbal agression of girls was higher than boys ( Card, A.N. , Sawalani, M. G.,Stucky, D. B. \& Little 2008). The same results for physical and verbal aggression of males and females were shown in another study of the University of California(Juvonen, J. \& Wang, Y. \& Espinoza, 2012).

A study in Germany reported that $43,7 \%$ of male adolescents and $23,6 \%$ of the females, interviewed, were involvrf in antisocial behaviours; $20,2 \%$ of males and $6,4 \%$ of females were involved in violent acts; $17,8 \%$ of males and $15,5 \%$ of females have caused physical violence; $29,9 \%$ of males and $7,1 \%$ of females were involved in acts of vandalism and $14,2 \%$ of males and $12,4 \%$ of females were involved in shop-lifting (Baier, et.al 2009, Marc Allroggen, München, 2013). The following empired studies for american adolescents from 15-18 old, showed important statistic datas where $32.8 \%$ of them showed physical aggression outside school, $40,7 \%$ of them were males and $24,4 \%$ females. While in school physical aggression showed $12 \%$ of them, in which $16 \%$ were males and $7.8 \%$ females( National Center for Injury Prevention and Control. Division of Violence Prevention 2012). While the studies show and the negativ relation between aggression and emotional intelligence of adolescents (Parker et. Al, 2001, Brejard et al, 2006, Kimiaei et al, 2011, Masoumeh, Bte Mansor, Yaacob, Abu Talib \& Sara, 2014).

In a study in another culture, in Iran where dominates life insecureness and the living with danger, is showed clearly that it has not emphased differences between the aggression of females and athlet males (Kharkan, Andam \& Mehdizadeh, Iran 2013.

It is very important for my study to be present and atent to understand the similarities and differences between boys and girls in their aggressive nature during development.Displaying aggressive behavior is supported by the personal social relations and social interaction. Still much discussed issue remains whether this aggressiveness is born or learned?

According to psychoanalyst Sigmund Freud and ethologist Konrad Lorenz, a supporter of the theory of instincts, all human beings possess aggressiveness in their birth, which together with sexuality are key elements in the development of the individual, finding their expression in behaviour individual performs. While many scholars treat aggressiveness as the primary force which may come as a reaction to aggression or frustration of primary needs.

Thus, according to John Dollard in 1930, known as one of the developers of hypothesis "Frustration - Aggression, aggression or bring frustrated conditions as inevitable response aggression (Conner, D. F, (2004)"Aggression and Antisocial Behavior in Children and Adolescents". Research and Treatment. The Guilford Press; 1 edition pg. 15). Albert Bandura famed Canadian psychologist focused his study of adolescent aggression to learning theory. Bandura theory 
insists on the fact that aggression is a learned behaviour. Albert Banduras scheme under which promote aggression is:"Model-Observation - Memorizing - Reinforcement - Behaviour".

\section{Actual context of Teenagers in Albania}

Not only for the purpose of study, but also to know more teenagers and their problems I went at many educational institutions, not wanting to dwell only on statistical data that represents of education ministry, as there students who are expelled from schoolfor violent acts or serious breaches regulations, presented simply as away.

To analyze the phenomenon of aggression and antisocial behaviour had to retain specific details that have school directories. In some of the major cities high schools noted that many male students lose academic year at the age of 16 17 years for the following reasons, placed according to the degree of action: drop from classes, violence against peers or school facilities as well as consumer and distribution of drugs within the school premises or alcohol.

Relying on the age of criminal behavior criminal literature ranges from $14-17$ years. Peak age of adolescence is the most important period for the full decision in forming opinion to prepare for life is when a teenager reaches 17 years (Lösel, $F$ \& Bliesener, 2003). At this age, he apparently did not feel no more need for the parent to the fact that larger conflicts parentchild occur at this age.

These were some of the reasons for the selection of the sample exactly my age of 17 years (plus, minus three months).

By contrast is less important cities where the number of students who lose the school year for these reasons it is very small and not significantly in rural areas where the reasons for leaving school when teenager leave towards one another residential center.

linitially focus precisely my study both women and men and to some of the key variables analysis of aggression, but of course I will not deny the fact that my interest was added to the study of female category due to data provided school leaders. For the first time only in 1999 jumped an important step in addressing girls and their aggression. Decades ago did not work in studying the phenomenon of girls, and finally social scientists, clinicians, educators and analysts directed their studies on this phenomenon to girls. It was the 1988 symposium "Development of Childhood" where he launched the idea of treating girls as neither in 1988 nor in publications Symposium 1991 world listing not girls, as their aggressiveness by excluding them. So and interference was unknown.

In schools there is no less problematic to female adolescents, as well as measures that schools have taken against them, the result was more relaxed and when they pose the same problems as boys.

For example, in cases not a few beatings within the school premises, girls, according to the degrees of normative provisions were given to three days measures expulsion from school and not the exception, as happened to the boys final. Many school leaders say the measures against girls may seem scarce, but in fact is not so, because their behaviours are not repeated as they boys or the fact that the girls try to within the school environment to behave more regular.

A smaller proportion of girls leave school due of truancy, the fact is that in our society, parents are more stringent and compelling to girls than to boys, even whenever they show their parents problematic cooperate more with the school.

\section{METHOD}

\section{Participans}

Student tested for these behaviors are both females and males (250,142/108 only quantitative study), 17 years old considered as the peak age of adolescence.They were in schools of metropolis, a large big city with heterogeneous populations, in a town with a population of homogenous, who live in different economical level, as well as in poor rural area.

\section{Procedure}

To test the students was used "Buss-Durkee Hostility Inventory "It contains 8 subscales. 
The test contains 75 statements and the students must choose if you agree or disagree with the statement. One of the reasons for the selection of this test was the analysis of the responses in detail the eight variables, each response assessed respectively by a point:

1.Assault, 2. Indirect hostility, 3. Irritability, 4. Negativism. 5. Resentment, 6. Suspicion,

7. Verbal hostility, 8.Guilt.

Teenagers were tested for the period January - April. They made sure that the questions were clear for each student. Of course I would like to thank the school administrators who created the possibility of testing adolescents, staff collaboration to discuss and get information on the social composition and phenomena with which they face daily in their work, as well as contact with school psychologist where the service function .

To measure the tendency of aggression in boys and girls found it logical to make this study not only in big cities increasingly on the move, in a city less important, but in rural areas, to make so possible to draw out some of the more specific elements of this phenomenon among adolescents in our society.

So are tested a total of 250 students aged 17 years, where 200 students were tested respectively in cities (in the graphic are marked with the name Urban Zone 1 and Urban Zone 2) and 50 students in a Rural Area RA.

It's too simple to say and express in keeping with general statistics, saying that young people are either non-aggressive or wanting to generalize, often can be made mistakes after this test clearly shows access or time trends indifferent areas, but never be diverted to their interpretation of the factors mentioned above, such as: genetic, social (here we can mention the effects arising from conflicting societies or in a very short period has undergone transformationspowerful naturally could not reflected in the social plan), individual, family factors, or in relationship.

I realize my research in a big city (ZU 1) that changing rapidly, a mobile cities, with a population more heterogje; in a city less important ( ZU 2) with a population more homogeneous composition of the population and not over populated, more conservative and less open to rapid change with a society less dynamic developments or commit professional individual throughout the day. Enabling not losing the constant contact with the child and in the mountainous rural area (RA) where life moves at a slower pace, where a significant number of people spend most of the day without any commitment, where adolescents are involved in farming and a agriculture work together with their parents

\section{Results}

\section{Table 1: Result of test aggression in girls}

\begin{tabular}{lllll}
\hline Dimensions & & Urban Zone 1 & Urban Zone 2 & Rural Area \\
\cline { 1 - 4 } Direct Assault & Girl & 44 & & 49 \\
Indirect Assault & Girl & 54 & 44 & 59 \\
Irritability & Girl & 49 & 55 & 48 \\
Negativism & Girl & 68 & 50 & 68 \\
Resentment & Girl & 55 & 69 & 53 \\
Suspicion & Girl & 60 & 54 & 63 \\
Verbal Assault & Girl & 57 & 60 & 50 \\
\hline Guilt & Girl & 56 & 57 & 60 \\
\hline
\end{tabular}

Females aggression compared with males (Figure 1) 


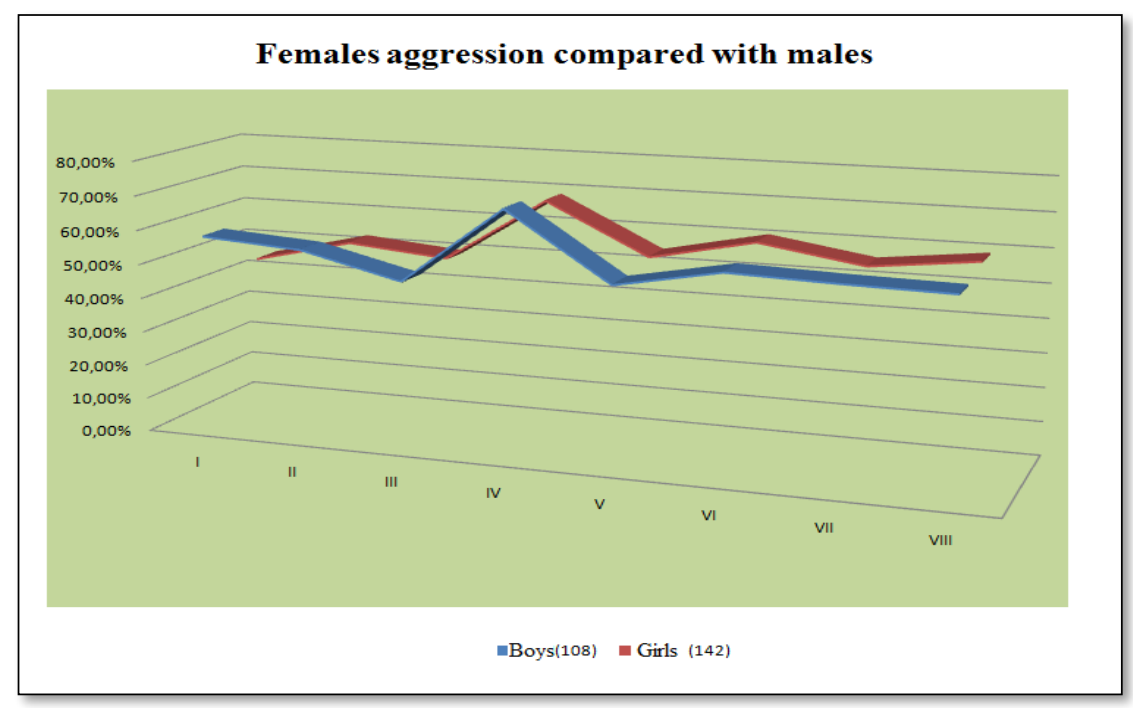

Of course seeing the test results can not prevailed a high tendency of aggressive girls compared with boys aggression. Will refer to the values of the graphic and see the results in accordance with each of the eight categories flaring category.

Physical aggression or direct where the difference between the tested boys from the girls reaches $13 \%$, and this value is quite acceptable considering developing muscles visible body of men, which is accompanied by physical force of boys at this age, but also the level the outcome of the girls considered high. If will see a test assertions "People who constantly bore deserve a punch to the face " boys are in favor of $75 \%$ and $80 \%$ of girls and even with such comments that not enough a punch, but maybe some.

The same can seeing on the 2. category "Indirect aggression against objects", where the difference between tested girls and boys is $4 \%$ higher in boys than in girls, but it is evident that the results are more than $50 \%$ of it in a way consistent to what we claimed leaders and teachers school. What catches the eye are the 3. Scale, Nervousness and 7.Scale, Verbal aggressiveness Scales where both sexes are almost at the same level with a difference of $1 \%$.

In 3.Scale with higher level girls, while in 7. Scale boys, but despite that if we were to take one category 7 claims. "If someone raises his voice, I lift more than it" girls who were tested were $84 \%$ in favor, even commenting until I heard only while the boys were $74.8 \%$ tested pro.

If refer to 4 . Scale "Negativism"both sexes result in a high level with a margin of $3 \%$ ranging from $68 \%$ to girls which is the highest value in $71 \%$ of boys.

If we observe carefully the category "Resentment" and "Guilt", resulting girls by a margin of $3 \%$ more than boys, and both categories with $50 \%$.

6. Scale "Suspicion" girls dominate over guys with a difference of $2 \%$ of the boys, but reaching a level $60 \%$ of all girls pro tested.

As can be observed in the graphic everybody girls and boys are dominant each ather in four categories, girls respectively in the "Irritability", "Resentment", "Suspicion" and "Guilt" scale, while the boys in the "Assault", "Indirect hostility", "Negativism" and "Verbal hostility" scale.

Obvious approach to boys and girls have an aggressive growth trend in total result in an overall aggressiveness girls $56 \%$, boys $57 \%$, a figure the more disturbing, which should attract the attention of the family, peer educators and all society and of course, considering the biological role of woman as wife and mother of future generations that will follow. 


\section{Conclusion and Recommendations}

According to Baillargen 2007 aggression and the its level both at males and females is not only close with adolescence, an age that is evident the individual vulnerability, the different interests and social, but also with the development of society where they live. The behaviours and their emotions are close with their family, society that are decisionable at their life.

Albanian society and family is having a long period of transition and with the democratic changes in 1991. Unfortunately there are not real studies for the level of aggressiveness, consume of alcohool, acts of violence in the family in the whole country,yet. According to the datas of this study and the high level of aggresiveness at teenagers oth males and females, in which each of them is owener to four different categories, is better that these studies to lay in a bigger popullation compaired this with the whole number of the population, environment and society in general and also compaired with the aspects of the development of teenagers in physical or emotional aspect.

Step by step is neccesery to start with programms to teduce the level of aggressiveness. The government colaborating with the educational institutions has to create more centres for the free time or sports centres for teenagers. These environments can be the places where they can leave their negative energies, aggressiveness and to own the ability to be part of social and human activities of showing their hobbies and passions, by feeling in this way with values. An important role has the educational institucions, which not only have to evident and punish the teenager, but with the parents has to find the solution for reducing,minimizing and stopping the aggressiveness or unsocial behaviours, by giving teenagers the oportunity to face this period of transition with less difficulties. Naturally the society by sensibilating has to be part of the creation of conditions of accepting the individ with this new status and to accept the role that wants to have in the society.

\section{References}

[1] Adams. Gerald R. (February 21, 2000) "Adolescent development" The Essential Readings, Wiley-Blackwell; 1 edition.

[2] Ausübel. David P(November, 2002) "Theory and Problems of Adolescent Development" Third Edition iUniverse; 3 edition.

[3] Bandura Albert, 1980 "Principles of Behavior Modification"Journal of Marketing.

[4] Berk. Laura E. (Dezember 2004) „Entwicklungspsychologie (Pearson Studium - Psychologie“ Addison-Wesley Verlag; Auflage: 3., aktualisierte Auflage.

[5] Berkowitz L : On the difference between intemal and extemal reactions to legitimate and illegitimate frustrations: A demonstration. Aggressive Behavior 7/ 83-96,1981.

[6] Berkowitz L : Frustrations, appraisals, and aversively stimulated aggression. Aggressive Behavior 14/3-11, 1988.

[7] Berkowitz, L. (1989). The frustration-aggression hypothesis:An examination and reformulation. Psychological Bulletin, 106(1), 59-73.

[8] Berkowitz, L. (2001) Affect, aggression, and antisocial behavior. In C. A. Anderson \& B. J.

[9] Bushman, (2002). Human aggression. Annual Review Psychology, 53, 27-51.

[10] Björkovist, K. (1994). Sex differences in physical, verbal, and indirect aggression: A review of recent research. Sex Roles, 30(3-4), 177-188.

[11] Breiling, J., Stoff. D. M.\& Maser Jack D. (October , 1997) "Handbook of Antisocial Behavior" Wiley; 1 edition.

[12] Buss-Durkee Hostility Inventory(2004)Guida ragionata agli strumenti diagnostici e terapeutici nel Disturbo' di gioco d'azzardo Patologico" Hans Dubois.

[13] Clarke David, September , 2003 "Pro-social and Anti-social Behaviour Taylor \& Francis".

[14] Connor MD. Daniel F. "Aggression and Antisocial Behavior in Children and Adolescents"

[15] Research and Treatment. The Guilford Press; 1 edition (July 12, 2004)

[16] Delfos. Martine F., London, 2004 "Children and Behavioural Problems" Anxiety, Aggression, 
[17] Depression and ADHD - A Biopsychological Model with Guidelines for Diagnostics and Treatment.

[18] Duncan B. Clark, M.D., Michael Vanyukov, \& Jack Cornelius, M.D., M.P.H. (November 2002)

[19] Childhood "Antisocial Behavior and Adolescent Alcohol Use Disorders Childhood" NIAAA Gimelli Ralph J.Normal Child and Adolescent Development. Amer Psychiatric Pub; 1 edition (May 1996)

[20] Fend Helmut, 1990"Vom Kind zum Jugendlichen. Der Übergang und seine Risiken"Entwicklungspsychologie der Adoleszenz in der Moderne. Huber vgl.

[21] Flexner William "Adolescence "Sarup \& Son ( Juny 2004)

[22] Geen Russell G. "Human Aggression" Open University 2001

[23] Heuves Willem, Frankfurt am Main 2010“Pubertät " "Entwicklungen und Probleme „ Hilfen für Erwachsene „.. Brandes und Apsel.

[24] Kaza Ndue , 2004, "Psikologji "-Zhvillimi i personalitetit Albania.

[25] Kaza Ndue, 2006 "Adoleshenca Stina e Shpërthimeve",Albania.

[26] Kazdin Alan E., 2005 "Parent Management Training. Treatment for Oppositional, Aggressive and Antisocial Behavior in Children and Adolescents" Oxford University Press. New York.

[27] Lösel, F \& Bliesener, Th."Aggression und Delinquenz unter Jugendlichen“,Germany, 2003.

[28] Myers, G.D., 1999 "Socialpsikologjia" development of adolescence" Scholarly Research Paper.

[29] Pepler Debra J. Kirsten C.Madsen, Christopher Webster, Kathryn S. Levene, 2004 "The Development and Treatment of Girlhood Aggression" Psychology Press.

[30] Reid John B. 2005, "Aggression, Antisocial Behavior, and Violence Among Girls: A Developmental Perspective

[31] Richardson "Human Aggression(1991). The Columbia Encyclopedia, Sixth Edition 2004, Columbia University Press.

[32] Rutter Michael Henri Giller \& Ann Hagell "Antisocial Behavior by Young People" Cambridge University Press; 1 edition (October, 1998)Greenwood Press Westport.

[33] Zahn Margaret A."The Delinquent Girl".Temple University Press (2009) 